\section{Gategory}

Synthesis of Natural

Products and

Potential Drugs

\section{Key words}

medium-sized ring formation

ketohydroxylation

SYNFACThen

J. J. FLEMING, J. DU BOIS* (STANFORD UNIVERSITY, USA)

A Synthesis of (+)-Saxitoxin

J. Am. Chem. Soc. 2006, 128, 3926-3927.

\title{
Synthesis of $(+)$-Saxitoxin
}<smiles>CS(=O)(=O)C(N)=NCC/C=C\C(NC(N)=S)C(N)CO</smiles>

$\mathrm{Mbs}=p-\mathrm{MeOC}_{6} \mathrm{H}_{4} \mathrm{SO}_{2}$<smiles>NC(=O)OC[C@@H]1NC([NH3+])N2CC[C@@H](O)NC23NC(=[NH2+])N[C@H]13</smiles>

$\beta$-Saxitoxinol

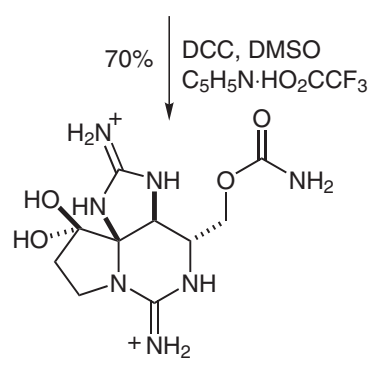

(+)-Saxitoxin $\frac{\text { 1) } \mathrm{Me}_{3} \mathrm{P}, \mathrm{THF}-\mathrm{H}_{2} \mathrm{O}}{\text { 2) } \mathrm{AgNO}_{3}, \mathrm{Et}_{3} \mathrm{~N}, \mathrm{MeCN}}$ $65 \%$ (2 steps)

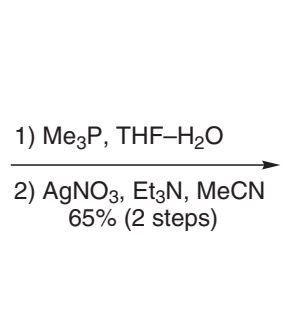

(

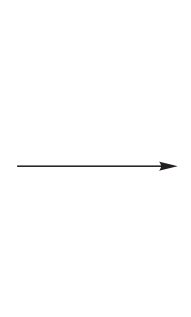<smiles></smiles>

Significance: $(+)$-Saxitoxin is a paralytic agent from oceanic red tides. It blocks cationic influx through voltage-dependent $\mathrm{Na}^{+}$channels. Notable features of the synthesis include formation of a medium-sized guanidine ring from a carbodiimide and regio- and stereoselective oxidation of alkene C to hydroxyketone $\mathbf{D}$
Comment: Reduction of azide $\mathbf{A}$ and immediate treatment with $\mathrm{AgNO}_{3}$ and $\mathrm{Et}_{3} \mathrm{~N}$ generated $\mathrm{N}$-sulfonylcarbodiimide $\mathbf{B}$ which reacted with the $\mathrm{C} 6$ amine to form a nine-membered ring. Carbamate C was regioselectively oxidized to hydroxyketone D which underwent nucleophilic addition to generate bicyclic E as a single stereoisomer. When $\mathrm{OsO}_{4}$ was used in the transformation of $\mathbf{C}$ to $\mathbf{D}$, the regioisomeric $\alpha$-hydroxyketone was obtained.

SYNFACTS Contributors: Philip Kocienski, Fiona Black 